\title{
Dinâmica de funcionamento da cadeia produtiva do mel no assentamento Tabuleiro Grande, Apodi/RN
}

\author{
Dynamics of functioning of the productive chain of the honey in Large Board \\ settlement, Apodi/RN
}

\author{
Francicláudio de Paula ${ }^{1}$; Karidja K. C. de F. Moura ${ }^{2}$; John L.V. Fonteles ${ }^{3}$; Kallyo H. S. Moura ${ }^{4}$
}

\begin{abstract}
RESUMO: A apicultura é considerada uma atividade secular, muito explorada por pequenos e grandes produtores rurais. É uma atividade em expansão em diversos países, inclusive no Brasil, pelo potencial de geração de trabalho e renda que possui, como também por contribuir para manutenção e preservação dos ecossistemas existentes. Mediante o exposto, essa pesquisa objetivou identificar a cadeia produtiva do mel em sua efetividade, no assentamento Tabuleiro Grande Apodi/RN, contribuindo para o desempenho operacional e eficiência. Como ferramentas para coletas de informação foram feitas visitas de observação e aplicados questionário com questões abertas e fechadas de cunho qualitativo e quantitativo. Identificou-se na pesquisa o nível de importância da apicultura para região estudada, interligando os aspectos sociais, econômicos e ambientais. Diante do exposto, pode-se concluir que a apicultura é importante e deve ser encarada como alternativa para a região estudada interligando os aspectos sociais, econômicos e ambientais, de forma que proporcione a agricultura familiar, a utilização da mão-de-obra familiar, fixação do homem ao campo e a prática da apicultura adequada caracteriza o desenvolvimento sustentável frente aos recursos naturais, muda à consciência dos produtores sobre a conservação do meio ambiente e, acima de tudo, gera renda, trabalho e alimento às famílias, além de favorecer o fortalecimento do associativismo na região.
\end{abstract}

Palavras-chave: cadeia produtiva, apicultura, desenvolvimento sustentável.

ABSTRACT: Beekeeping is considered a secular activity, much exploited by small and large farmers. Is a growing activity in several countries, including Brazil, the potential for generation of employment and income that has, as well as for contributing to maintenance and preservation of existing ecosystems. Through the above, this research aimed to identify the productive chain of the honey in its effectiveness, on the Big Board settlement Apodi/RN, contributing to operational performance and efficiency. As tools for collections of information and observation visits were made applied questionnaire with open and closed questions of qualitative and quantitative nature. The research identified the level of importance of beekeeping to the region studied, connecting the social, economic and environmental aspects. Given the above, it can be concluded that beekeeping is important and should be seen as an alternative for the region studied by the social, economic and environmental aspects, in order to provide family farming, the use of labour in the family, fixing the man to the field and the practice of beekeeping suitable features sustainable development forward to natural resources, change the consciousness of producers on the conservation of the environment andabove all, generates income, employment and food to families, as well as to encourage the strengthening of associations in the region.

Keywords: productive chain, beekeeping, Sustainable Development.

\footnotetext{
*Autor para correspondência

Recebido para publicação em 12/08/2014; aprovado em 25/02/2015

${ }^{1}$ Especialista em Gestão Ambiental - Faculdade do Vale do Jaguaribe (FVJ)/ Assessor Territorial de Inclusão Produtiva - Alto Oeste Potiguar (MDA/SDT/CNPq/UERN) E-mail: franciclaudio30@hotmail.com

${ }^{2}$ Pesquisadora/Professora PNPD/CAPES - UFERSA, Mossoró, RN, Departamento de Ciências Ambientais e Tecnológicas (Setor Solos),Av. Francisco Mota, 572, CEP 90.625-900. E-mail: karidja@ufersa.edu.br

${ }^{3}$ Aluno da graduação, Bolsista PICI - UFERSA, Mossoró, RN, Av. Francisco Mota, 572, CEP 90.625-900. E-mail: lenonce@ gmail.com

${ }^{4}$ Mestre em Fitotecnia - Universidade Federal Rural do Semiárido (UFERSA)/ Consultor do SEBRAE-RN- E-mail: kallyojr@gmail.com
} 


\section{INTRODUÇÃO}

As abelhas surgiram no Continente Asiático há aproximadamente 45 milhões de nos, e começaram a ser exploradas, racionalmente, pelo homem desde 2.400 a.C. Atualmente, a Apicultura, é aproveitada em forma econômica pelo homem na polinização das plantações, assim como na produção de própolis, geléia real e apitoxina e o mais conhecido e explorado pelo homem que é o mel, pois além de ser uma rica fonte de alimento, o mel também é muito utilizado na medicina caseira (GONZAGA, 1998).

Segundo Henrique et al. (2008) a apicultura é uma das atividades capaz de causar impactos positivos, tanto sociais, ambientais quanto econômicos, além de contribuir para a manutenção e preservação dos ecossistemas existentes. A cadeia produtiva da apicultura propicia a geração de inúmeros postos de trabalho, empregos e fluxo de renda, principalmente no ambiente familiar, sendo, dessa forma, determinante na melhoria da qualidade de vida, preservação do meio ambiente, melhoria da renda familiar e fixação do homem no meio rural.

A apicultura é considerada uma das atividades mais promissoras para a região do semi-árido por aproveitar o potencial apícola existente, gerar renda e ocupação ao homem do campo, além do apelo ecológico, já que o pasto empregado na produção apícola é nativo. O Nordeste possui um dos maiores potenciais apícola do mundo, sendo uma das poucas do mundo com possibilidade de produzir o mel orgânico em grande quantidade, devido à existência de extensas áreas onde não se utilizam agrotóxicos nas lavouras (HENRIQUE, 2008).

O resultado mais importante da implementação da apicultura na região Nordeste do Brasil é a conservação do ecossistema, que por falta de alternativa para a sobrevivência do sertanejo tem sido degradado com a retirada de lenha, desmatamentos e queimadas. A conservação e o uso racional destas áreas representam a manutenção da vida na região, motivo pelo qual a implementação da atividade apícola é tão importante (SANTOS, 2009).

Este estudo teve como objetivo identificar a cadeia produtiva do mel em sua efetividade, no assentamento Tabuleiro Grande Apodi/RN, contribuindo assim para o desempenho operacional e eficiência desta atividade.

\section{MATERIAL E MÉTODOS}

O levantamento foi realizado na comunidade Tabuleiro Grande no Município de Apodi, localizado na mesorregião Oeste Potiguar, microrregião da Chapada do Apodi (Brasil, 2005), no Estado do Rio Grande do Norte, a $5^{\circ} 39^{\prime} 50^{\prime \prime} \mathrm{S}$ e $37^{\circ} 47^{\prime} 56^{\prime \prime W}$, a cerca de $334 \mathrm{~km}$ da Capital, em uma área de $1.549 \mathrm{~km}^{2}$ (Brasil, 2005). Sua classificação climática, conforme Köppen, é do tipo Bswh, clima quente e semiárido, com temperatura média anual de $28,1^{\circ} \mathrm{C}$, umidade relativa média anual de $68 \%$ e 2.700 horas de insolação. O município apresenta precipitação pluvial anual média em torno de $833,5 \mathrm{~mm}$ e período chuvoso concentrado nos meses de março a maio (GOVERNO DO RIO GRANDE DO NORTE, 2010).

A tipologia central desta pesquisa é a investigação teórico-empírica que, para Garcia e Fadel (2012), deve "interagir com as abordagens teóricas, mas ao mesmo tempo pontuando com os dados coletados e suas análises a partir da observação de realidade".

Desta maneira, Laville e Dionne (1999, p. 85-86 apud GARCIA; FADEL, 2012) notificam que este tipo de pesquisa objetiva contribuir para "aumentar a soma dos saberes disponíveis, mas que poderão, em algum momento, ser utilizados com a finalidade de contribuir para a solução de problemas posto pelo meio social".

A Pesquisa ocorreu sob dois aspectos: revisão de literatura (pesquisa bibliográfica - texto) e coleta de dados (questionários) como fundamento para a pesquisa teóricoempírica.

Sobre a pesquisa bibliográfica, Severino (2008, p. 122) mostra que "é aquela que se realiza a partir do registro disponível, decorrente de pesquisas anteriores, em documentos impressos, como livros, artigos, teses etc. Utiliza-se de dados ou categorias teóricas já trabalhados por outros pesquisadores e devidamente registrados".

Também, aplicou-se um questionário (coleta e análise quantitativa e qualitativa). $\mathrm{O}$ questionário, segundo Gil (1999, p.128), pode ser definido "como a técnica de investigação composta por um número mais ou menos elevado de questões apresentadas por escrito às pessoas, tendo por objetivo o conhecimento de opiniões, crenças, sentimentos, interesses, expectativas, situações vivenciadas etc.".

Para esta investigação, utilizou-se da amostragem intencional, que Martins (2002) trata como aquela em que é escolhido, intencionalmente, um grupo de elementos que irá compor a amostra. $\mathrm{O}$ pesquisador procura, intencionalmente, saber a opinião daquele respectivo grupo. Percebendo estes aspectos, foram aplicados questionários com $100 \%$ dos apicultores do assentamento.

Os dados coletados foram tratados de forma quantitativa e quantitativa, utilizando-se de procedimentos estatísticos e descritivos. Esse método possibilita a análise e interpretação dos resultados.

\section{RESULTADOS E DISCUSSÃO}

Durante a pesquisa realizada na associação dos apicultores, no que se refere ao quesito capacitação para desenvolvimento da atividade apícola, constatou-se que $63 \%$ responderam que recebem capacitação, $37 \%$ deles disseram não, visto que estes chegaram à comunidade recentemente, e os treinamentos ofertados foram realizados no início da formação da associação dos apicultores. A participação dos produtores em eventos relacionados à atividade apícola poderá refletir diretamente na organização e em uma maior produção, já que os mesmos estão sempre buscando novas informações para um melhor desenvolvimento da atividade.

Vale ressaltar que um dos principais motivos do insucesso de determinados produtores na atividade apícola é a falta de capacitação para tal atividade, para Vilela e Pereira (2002) ocorreu um rápido crescimento da atividade apícola a partir de 1996 que foi da ordem de 10,43\% ao ano, chegando a $25,40 \%$ em 2000 , o que motivou a muitos produtores ingressarem na atividade sem a capacitação necessária para desenvolvê-la de maneira correta, sendo muitos destes produtores motivados principalmente pelo rápido retorno financeiro da atividade.

Com relação a inspeção sobre o alimento produzido, as respostas foram as seguintes: $63 \%$ responderam 
que sim, a produção é inspecionada pela COOPERVIDA, que presta assistência técnica à comunidade e $37 \%$ disseram que não recebem , pois no período e data marcada os produtores estão muitas vezes ausente da comunidade e por exercerem outras atividades. Segundo Dantas et al. (2007) a assessoria técnica da COOPERVIDA vem dando uma "injeção de ânimo" nas comunidades, realizando o acompanhamento as atividades nas áreas produtivas semanalmente sendo que, para cada dia da semana faz-se uma vistoria em cada assentamento

No que se refere ao estado de conservação da casa de mel, constatou-se que os apicultores têm cuidado com conservação da mesma, onde $69 \%$ responderam que a mesma encontra-se em bom estado de conservação, 26\% acharam que poderia ser melhorado é $5 \%$ disseram que está excelente (Figura 1).

Quanto ao uso de EPI'S, 74\% disseram usar os equipamentos de proteção e $26 \%$ que responderam que ainda faltam equipamentos adequados para o manejo, especialmente no processo de desopeculação. De acordo Azolini \& Costa (2006), a criação racional de abelhas exige roupas e equipamentos específicos. Todas as pessoas que vão ter contato com as abelhas devem usar vestimenta adequada, composta de chapéu, máscara, macacão, botas, luvas.

Figura 1 - Conservação da Casa do Mel.

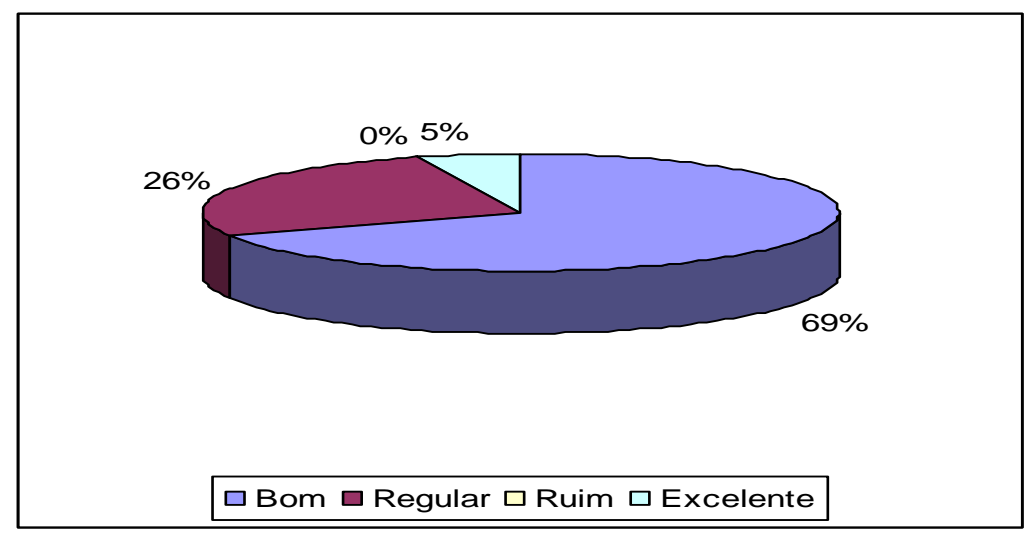

No quesito que se refere ao processo de esterilização dos equipamentos da casa do mel, constatou-se que $63 \%$ dos produtores de mel responderam que o processo de esterilização dos equipamentos da casa de mel só é necessário no período da colheita, $26 \%$ responderam que seria

Figura 2 - Processo de esterilização das ferramentas. interessante a esterilização uma vez por mês e $11 \%$ disseram que a esterilização deveria ser semanal (Figura 2). Percebendo-se que a maioria dos associados acha importante manter os equipamentos limpos, pois é um local onde manipulam o mel.

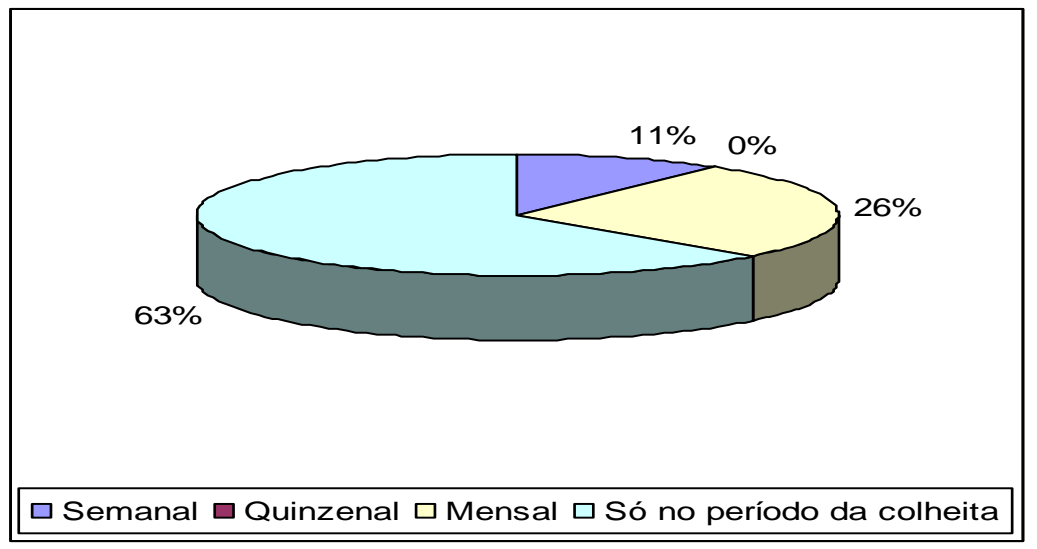

Vale ressaltar que procedimentos irregulares, entre eles a falta de higienização dos equipamentos se traduz em perda da qualidade e geração de desconfiança dos consumidores.

No quesito armazenamento de mel, $100 \%$ dos entrevistados responderam que armazena seu produto com muito cuidado, em decantador, deixando em repouso no período adequado até sua comercialização.

Segundo Moura et al. (2013), a implantação efetiva das boas práticas apícolas aponta para uma maior garantia de produção de alimento seguro, obedecendo a critérios de higiene desde o campo, no qual os grupos organizados atendem a normas pré-estabelecidas e diminuem os riscos de qualidade no mel.

De acordo com as respostas colhidas pelos apicultores $74 \%$ responderam que o processo executado para colheita das melgueiras é feito com muito cuidado (bom). E $26 \%$ responderam que há necessidade de melhoramento (regular), pois se observa desperdício do mel e morte de abelhas, quanto aos requisitos ruim e excelente não foi opinado (Figura 3). 
Figura 3 - Processo de colheita das melgueiras.

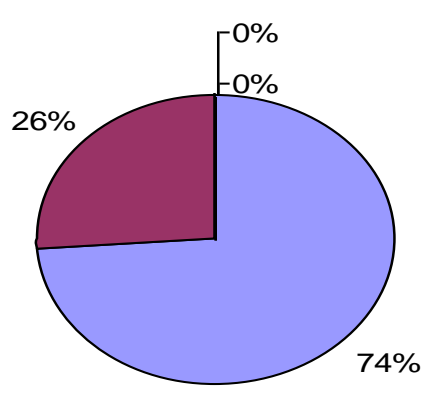

$\square$ Bom $\square$ Regular $\square$ Ruim $\square$ Excelente

Segundo dados colhidos de questões abertas, quando questionados a cerca do que eles acham sobre a atividade apícola, os mesmos foram unânimes em responder que a produção de mel é uma das melhores atividades desenvolvidas no assentamento, pois os mesmos não tem muitas despesas com o manejo, enquanto as culturas exige muito trabalho, como os caprinos e os outros animais. Segundo Fonseca (2010) para os agricultores da região de Apodi, a atividade apícola é uma das melhores em termos de lucros, pois é de fácil manejo, garante e assegura a propagação das espécies nativas evitando que essas plantas possam vir a ser destruídas, tendo um excelente retorno econômico.

De acordo com figura 4, no que se refere ao período de armazenamento do mel no decantador, $37 \%$ dos entrevistados responderam que o mel fica armazenado por dois dias, 32\% deles responderam que deixa o mel no decantador por três dias, $26 \%$ falaram que seu mel fica armazenado acima de três dias não tendo mel de outro associado para decantar ou não tendo venda e $5 \%$ disseram que o mel fica um dia e que acha um tempo bom para o repouso do mel.

Figura 4 - Período de armazenamento do mel no decantador.

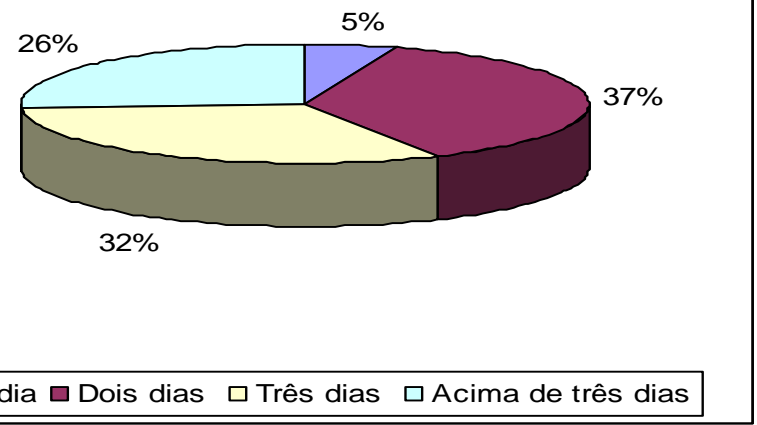

Com relação ao tipo de material usado nos fumigadores, $72 \%$ dos entrevistados responderam que usam pó de serraria, $18 \%$ usam pedaços de pau de cumaru, $5 \%$ usam imburana e pinhão, disseram que existe muito cuidado quanto ao uso do material nos formigadores, pois usando material indevido podem prejudicar o sabor do mel (Figura 5).

Figura 5 - Material usado nos formigadores.

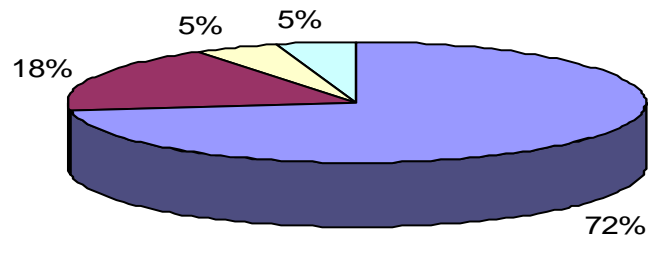

$\square$ Pó de serraria $\square$ Cumaru $\square$ Imburana $\square$ Pinhão 
Segundo Moura (2013), cupinzeiro, palha de feijão e palha de arroz são materiais que não são recomendados para a utilização na queima no fumigador. Dos utensílios, o fumigador é obrigatório, pois a partir da combustão de cavacos, sabugo de milho e materiais não tóxicos, produz fumaça para tornar as abelhas menos agressivas (AZOLINI, 2006).

No que se refere aos cuidados no manuseio da cera dos quadros, $95 \%$ dos entrevistados responderam que são cuidadosos no momento da troca da cera dos quadros, fazendo com que permaneça a produção já existente, notando que no período de desopeculação se desgasta boa parte dos alvéolos, local onde as abelhas produzem o mel. Os $5 \%$ desconhecem a forma correta do manuseio.

Assim sendo, verificou-se que ainda há despreparo de alguns apicultores durante o manejo, deixando prevalecer alguns hábitos inadequados durante o processo produtivo, acarretando cada vez mais a distância da eficiência para competitividade no mercado.

Com relação ao quesito, uso de roupas e equipamentos adequados para manutenção, maneio e colheita do mel, $60 \%$ dos apicultores responderam que usam as roupas e equipamentos recomendados, enquanto $40 \%$ responderam que não tem essa preocupação, esse resultado revela a falta de consciência dos procedimentos necessários ao processo de manipulação/produção do mel. Havendo necessidade de ajustes, a fim de alcançar padronização e qualidade sanitária.

Segundo Moura (2013), a utilização das Boas Práticas Apícolas é uma ferramenta eficiente para diferenciar os apicultores e diminuir os possíveis perigos do mel de abelhas do campo ao processamento no local extração.

Referindo-se a questão que retrata a importância da conservação do meio ambiente para atividade apícola (Gráfico 6), foi percebido que todos os apicultores responderam que é de grande importância conservar o meio ambiente, além da produção de alimentos para nossa fauna, a comunidade retira casca de árvore para fazer medicamentos proporcionando a cura de diversas doenças.

Entretanto, constata-se que os apicultores estão totalmente preocupados com os impactos ambientais, evitando as queimadas e derrubas de árvores, porém existe uma política de reflorestamento da vegetação nativa dentro da comunidade, fortalecendo a preservação do meio ambiente.

Figura 6 - Conhecimento sobre a conservação do meio ambiente.

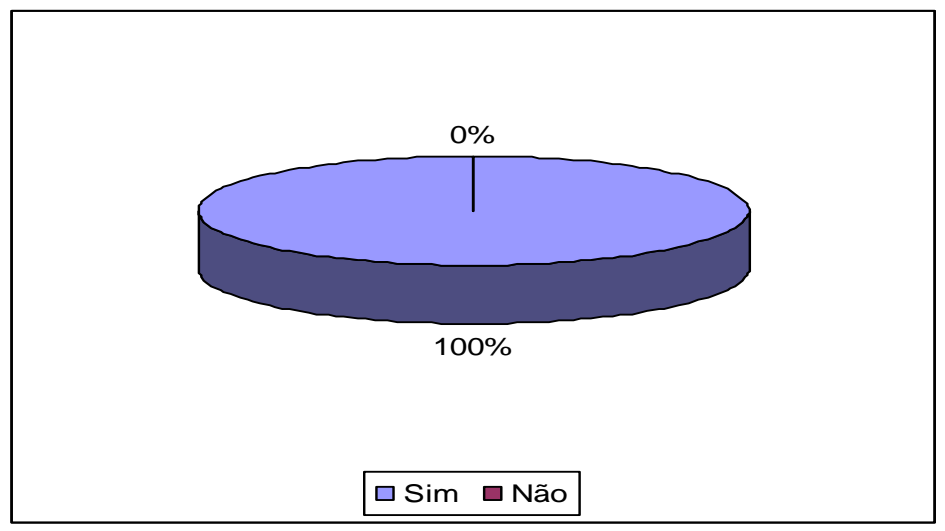

De maneira geral, a apicultura tem, portanto, modificado a paisagem dos agroecossistemas e a vida das famílias, colaborando na recomposição da vegetação com a implantação de espécies nativas e ainda por conservar e garantir a biodiversidade. Bem como, favorece ao oferecimento de alimentos mais saudáveis e melhora a qualidade de vida das famílias produtoras.

Quando questionados se a associação tem objetivos para expandir a produção apícola, $100 \%$ dos apicultores responderam que sim, espera-se aumento na produção, melhoraria nas instalações da casa do mel, mais investimentos em treinamentos, montar uma cooperativa dentro da comunidade e aumentar o número de apicultores.

No que se refere a venda do mel, 95\% dos apicultores responderam que as vendas realizadas na associação e de maneira coletiva, os recurso adquiridos são destinados para todos os sócios e não individual. Atualmente a associação dos apicultores do Assentamento Tabuleiro Grande vendem seu produto para atravessadores e cooperativas como: COAFAP E COOAPAPI.

Segundo Dantas (2007), embora que a produção de mel de Apodi seja relativamente grande, os produtores têm dificuldades para vender grandes quantidades de mel. Para minimizar essas dificuldades, irão juntar toda a produção dos assentamentos para vender em conjunto.

No que se refere a comercialização de outros produtos atrelados a atividade apícola, 89\% dos apicultores responderam que existe projeto para produção de própoles, aumento da produção de mel, melhoramento da casa do mel e também a produção de outros produtos extraídos das abelhas. Os $11 \%$ disseram que não tem conhecimento de projetos futuros. Observando-se que os assentados ainda possuem pouca diversificação de produtos apícolas, podendo este resultado ser devido ao pouco tempo que os mesmos dispensam para essa atividade, uma vez que estes ainda se dedicam a outras atividades agropecuárias e agrícolas.

Segundo Sousa (2013), em estudo realizado em três assentamentos rurais observou-se que no assentamento Jacu $90 \%$ dos produtores pesquisados produzem apenas mel e $10 \%$ produzem mel e cera, isso pode esta associada ao pouco tempo dos mesmos na atividade. Já no assentamento Fortuna $40 \%$ produzem apenas mel e $60 \%$ produzem mel e cera. No assentamento Acauã $30 \%$ produzem apenas mel, $60 \%$ produzem mel e cera e $10 \%$ produzem mel, cera e própolis. Observa-se que os produtores da comunidade Acauã já possuem uma produção mais diversificada podendo ser fruto de um tempo maior que os mesmo possuem na atividade. 
Quanto à comercialização os produtores têm uma visão voltada para a adaptação da exigência do mercado partindo do princípio produtivo, para possível certificação, Serviço de Inspeção Federal-SIF, contribuído ainda mais para o desenvolvimento do produto visando atingir outros mercados, como também, outros produtos, como a própolis, cera e outros, fortalecendo a economia local.

De maneira geral, através da pesquisa realizada no assentamento Tabuleiro Grande apodi/RN, detectou-se existência de falhas nos processos executados por alguns apicultores, assim sendo, recomenda-se que os apicultores devem encarar suas atividades buscando cada vez mais a educação contínua, treinamento e está sempre acompanhando as mudanças existentes, para se equiparar aos melhores produtores, fortalecendo a criação de emprego e renda para toda a comunidade.

\section{CONCLUSÕES}

Embora a apicultura apresente destaque na região estudada verifica-se que ainda necessita superar algumas dificuldades, como falta de organização dos produtores nos planejamentos, ausência de programas para desenvolvimento da apicultura e assistência técnica adequada e dificuldades em comercializar a produção.

Identificou-se, ainda, que mesmo sendo uma atividade geradora de vasta diversidade de produtos (mel, própolis, cera, geléia real, apitoxina, etc.), os apicultores do assentamento Tabuleiro Grande potencializam apenas a produção do mel sendo de conhecimento dos mesmos, os serviços à natureza (preservação do meio ambiente, através da polinização da flora nativa), ainda, não são explorados na sua dimensão.

Diante da situação encontrada recomenda-se que os produtores se profissionalizem, participando de eventos da área; que as autoridades governamentais desenvolvam programas de incentivo à prática da apicultura como alternativa para recomposição da reserva legal e matas ciliares. Além disso, que os apicultores passem a explorar mais o potencial apícola, visando à exportação não só do mel, como também de todos os demais produtos da colmeia e diversifique a produção e utilizem os produtos apícolas na manipulação de alimentos e medicamentos alternativos.

Uma alternativa é a exploração da produção do mel orgânico; desenvolvendo marketing específico para aumentar o consumo de mel nas famílias e, também nas escolas e abrigos de idosos etc. e utilizem o cultivo de plantas medicinais para a pastagem apícola e, também, como fonte alternativa de renda para a propriedade.

Diante do exposto, pode-se concluir que a apicultura é importante e deve ser encarada como alternativa para a região estudada interligando os aspectos sociais, econômicos e ambientais, de forma que proporcione a agricultura familiar, a utilização da mão-de-obra da família, fixação do homem ao campo e a prática da apicultura adequada caracteriza o desenvolvimento sustentável frente aos recursos naturais, muda à consciência dos produtores sobre a conservação do meio ambiente e, acima de tudo, gera renda, trabalho e alimento às famílias, além de favorecer o fortalecimento do associativismo na região.

\section{REFERÊNCIAS BIBLIOGRÁFICAS}

AZOLINI, V.; COSTA, V. M. H. de M. A utilização da informação contábil para a gestão da apicultura de pequeno porte. Revista Uniara, Araraquara - SP, n. 17/18, 2005/2006, p. 145-154.

BRASIL. Ministério de Minas e Energia. Serviço Geológico do Brasil. Secretaria de Geologia, Mineração e Transformação Mineral. Projeto cadastro de fontes de abastecimento por água subterrânea: Rio Grande do Norte: diagnóstico do Município de Apodi. Recife: CPRM, 2005. 10p.

DANTAS B. L.; LIBERALINO FILHO J.; LIRA J. F. B. DE; MARACAJÁ P. B.; DINIZ FILHO E. T.; A agroecologia nos assentamentos de: Moaci Lucena, Sítio do Góis e Vila Nova em Apodi - RN. Infotecnarido, Mossoró - RN, v.1, n.1, p.01-12 de janeiro/março de 2007.

FONSECA, I.; LIBERALINO FILHO, J; DANTAS, B.; SIZENANDO FILHO, F.; NASCIMENTO, F. Assessoria técnica, social e ambiental em seis assentamentos de reforma agrária no município de Apodi-RN. informativo técnico do semiárido Mossoró RN, v.2, n.1, p.10-14 de janeiro/dezembro de 2008.

GARCIA, R.; FADEL, B. A Percepção do indivíduo na gestão do conhecimento organizacional: estudo teórico-empírico das influências da interferência nos fluxos informacionais na criação de conhecimento e tomada de decisão. Disponível em:<http://www.facet.br/novo/3fem/Encontro/Arquivos/ Regis_Garcia_e_Barbara.pdf $>$. Acesso em: 04 out. 2012.

GIL, Antônio Carlos. Métodos e técnicas de pesquisa social. 5. ed. São Paulo: Atlas, 1999.

GOVERNO DO RIO GRANDE DO NORTE. Instituto de Desenvolvimento Sustentável e Meio Ambiente do RN. Perfil do seu município. Disponível em: <http://www.idema.rn.gov.br/contentproducao/aplicacao /idema/socio_economicos/ arquivos/apodi/apodi.doc>. Acessado em: 10 mar. 2010.

GOnZAGA, S. R. Cera de abelhas. In: Anais de XII Congresso Brasileiro de Apicultura. Salvador Bahia. 1998.

HENRIQUE R. G.; PEREIRA D. S.; OLIVEIRA A. M. DE; MEDEIROS P. V. Q. DE; CUNHA F. F. Perfil dos produtores familiares de mel no município de Serra do Mel - RN. Revista Verde, Mossoró - RN, v.3, n.4, p2941, outubro/dezembro de 2008.

MARTINS, Gilberto de Andrade. O Processo de pesquisa. In: Manual para elaboração de monografias e dissertações. 3. ed. São Paulo: Atlas, 2002.

MOURA, S. G.; MURATORI M. C. S.; MONTE A. M.; CARNEIRO R. M.; SOUZA D. C.; ALENCAR L. C. 
Perfil sanitário dos apicultores Piauienses quanto às boas práticas apícolas. Scientia Plena, São Cristóvão - SE, v. 9, n. 5, 2013.

RETORTA, M. S. Percepções do professor sobre o SAEB: um estudo sobre o efeito retroativo. Revista Educação \& Tecnologia, Curitiba, n. 10, p. 133-174, mai. 2010.

SANTOS C. S. DE; RIBEIRO A. DE S. Apicultura uma alternativa na busca do desenvolvimento sustentável. Revista Verde, Mossoró - RN, v.4, n.3, p. 01- 06, julho/setembro de 2009.

SILVA, E. G. da. PRODUÇÃO E COMERCIALIZAÇÃO DE PRODUTOS APÍCOLAS NOS MUNICÍPIOS DE AQUIDAUNA E ANASTÁCIO/MS. 2007. Dissertação (Mestrado em Geografia). Universidade do Estado de mato Grosso de Sul. Aquidauna. 2007.

SEVERINO, Antônio Joaquim. Teoria e prática científica. In: . Metodologia do trabalhado científico. 23. ed. rev. e atual. São Paulo: Cortez, 2008.

SOUSA, Luci Cleide Farias Soares. Sustentabilidade da apicultura: aspectos socioeconômicos e ambientais em assentamentos rurais no semiárido paraibano. $68 \mathrm{f}$. Dissertação (Mestrado em Sistemas Agroindustriais) Universidade Federal de campina Grande, Centro de Ciências e Tecnologia Agroalimentar, Pombal, 2013.

VILELA, S. L. O.; PEREIRA, F. M. (Org). Cadeia produtiva do mel no Estado do Rio Grande do Norte. Natal: SEBRAE/RN, 130p, 2002. 